\title{
Implementasi Kriptografi Untuk Pengamanan Data Pribadi Siswa SMA Swasta Jaya Krama Beringin Dengan Algoritma RC4
}

\author{
Rinaldi Maulana $^{1 *}$, R. Mahdalena Simanjorang ${ }^{2}$ \\ ${ }^{1,2}$ STMIK Pelita Nusantara \\ Jl. Iskandar Muda No. 1 Medan 20154 Indonesia \\ Corresponding author's e-mail: rinaldimaulana823@gmail.com
}

\begin{abstract}
Abstrak - Data pribadi siswa SMA Swasta Jaya Krama Beringin diperlukan dalam pendataan administrasi oleh pihak sekolah. Data pribadi meliputi identitas diri siswa seperti Nama Siswa, Nomor Induk Keluarga (NIK), Jenis kelamin, alamat, nomor handphone, e-mail,dan lain sebagainya. dalam era digital saat ini data adalah segalanya, dengan perkembangan jaringan internet yang semakin mudah untuk diakses, perlu tahu dan sadar atas hal-hal apa saja yang merupakan data pribadi dan apa yang seharusnya dilakukan untuk melindungi data pribadi tersebut. Permasalahan penelitian adalah keamanan data pribadi siswa SMA Jaya Krama Beringin perlu mendapat perhatian disebabkan maraknya terjadi pencurian data oleh hacker untuk disalahgunakan maka diperlukan kebutuhan software komputer untuk keamanan data. Langkah pertama dalam tahapan Algoritma RC4 adalah melakukan proses KSA (Key Schedulling Algorithm) dimana pada tahap ini merupakan proses pembentukan S-Box (Array S) dengan panjang 256 byte (indeks 0 sampai 255) berdasarkan kunci enkripsi. Setelah menggunakan operasi XOR pada chipertext dengan kunci, maka hasil XOR bilangan biner yang didapat diubah menjadi plaintext.
\end{abstract}

Kata kunci: Keamanan Data, Kriptografi, Enkripsi, Deskripsi, RC4

Abstract - The personal data of the Jaya Krama Beringin Private High School students is required in the administrative data collection by the school. Personal data includes student identification such as student name, family identification number (NIK), gender, address, mobile number, e-mail, and so on. In today's digital era data is everything, with the development of the internet network that is increasingly easy to access, it is necessary to know and be aware of what things are personal data and what should be done to protect personal data. The research problem is that the personal data security of Jaya Krama Beringin High School students needs attention due to the widespread occurrence of data theft by hackers to be misused, it is necessary to need computer software for data security. The first step in the RC4 algorithm stage is to carry out the KSA (Key Scheduling Algorithm) process which at this stage is the process of forming an S-Box (Array S) with a length of 256 bytes (index 0 to 255) based on the encryption key. After using the XOR operation on the ciphertext with the key, the XOR result of the binary number obtained is converted into plaintext.

Keywords: Data Security, Cryptography, Encryption, Description, RC4

\section{Pendahuluan}

Dalam kemajuan teknologi yang sangat cepat dan akurat telah mengalami perkembangan setiap informasi dalam bidang pendidikan untuk terus berusaha meningkatkan kemampuan dalam mengelola suatu data-data dan informasi yang aman dan efisien karena sangat dibutuhkan dalam bidang pendidikan. Penulisan sebuah informasi saat ini juga tidak lepas dari teknologi-teknologi kecanggihan yang ada pada saat ini. Hal ini masih banyak dari pihak instansi yang belum menggunakan atau mengelola teknologi secara maksimal, yang dimana teknologi ini sangat berguna untuk memudahkan pihak sekolah dalam mengamankan data dan informasi siswa, sehingga memudahkan kinerja operator sekolah di SMA Swasta Jaya Krama Beringin.

Keamanan data merupakan hal penting dalam menjaga kerahasiaan data-data tertentu yang hanya boleh diketahui oleh pihak yang memiliki hak saja, salah satu cara untuk menjaga keamanan dan kerahasiaan suatu data dengan enkripsi dan dekripsi untuk membuat data agar tidak dapat dibaca atau dimengerti oleh sembarang orang [1]. Teknik pengamanan data menggunakan enkripsi dan deskripsi dikenal dengan nama kriptografi, salah satu cara untuk mengamankan data, yaitu dengan menyandikan pesan asli (plaintext) ke dalam bentuk pesan rahasia (ciphertext). Proses pengamanan ini melibatkan algoritma dan kunci. Kunci enkripsi dapat dengan mudah mengembalikan plaintext dari ciphertext [2]. Oleh karena itu diperlukan algoritma kriptografi yang kuat. Dengan berkembangnya ilmu penyandian, orang dapat dengan mudah memperoleh kunci penyandian lewat berbagai macam cara.

Algoritma kriptografi Rivest Code 4 (RC4) merupakan salah satu algoritma kunci simetris dibuat oleh RSA Data Security Inc (RSADSI) yang berbentuk stream chiper [3][4]. RC4 menggunakan panjang kunci dari 1 
sampai 256 byte yang digunakan untuk menginisialisasikan tabel sepanjang 256 byte. Tabel ini digunakan untuk generasi yang berikut dari pseudo random yang menggunakan XOR dengan plainteks untuk menghasilkan cipherteks. Masing-masing elemen dalam tabel saling ditukarkan minimal sekali. RC4 merupakan merupakan salah satu jenis stream cipher, yaitu memproses unit atau input data pada satu saat. Dengan cara ini enkripsi atau dekripsi dapat dilaksanakan pada panjang yang variabel. Algoritma ini tidak harus menunggu sejumlah input data tertentu sebelum diproses, atau menambahkan byte tambahan untuk enkripsi [5] Metode enkripsi RC4 sangat cepat kurang lebih 10 kali lebih cepat dari DES [6].

Penelitian Implementasi Algoritma RC4 pada Sistem Pengamanan Dokumen Digital Soal Ujian, menjelaskan algorima kriptografi RC4 merupakan jenis stream cipher. Kelebihanya adalah dengan menggunakan cara ini enkripsi algoritma RC4 dapat dilakukan pada data dengan panjang yang beragam [7]. Penelitian Pengamanan Citra Digital Berdasarkan Modifikasi Algoritma RC4 Algortima RC4 bekerja dengan tiga tahap utama yaitu Key Scheduling Algorithm (KSA), Pseudo Random Generation Algorithm (PRGA) dan proses Enkripsi dan Dekripsi [8].

\section{Tinjauan Pustaka}

\subsection{Kriptografi}

Kriptografi merupakan ilmu sekaligus seni untuk menjaga keamanan pesan, selain itu ada pengertian tentang kriptografi yaitu kriptografi merupakan ilmu yang mempelajari teknik-teknik matematika yang berhubungan dengan aspek keamanan informasi seperti kerahasiaan, integritas data, serta otentikasi. Plaintext merupakan pesan asli yang belum disandikan atau informasi yang ingin dikirimkan atau dijaga keamanannya. Ciphertext merupakan pesan yang telah disandikan (dikodekan) sehingga siap untuk dikirimkan [9]. Enkripsi merupakan proses yang dilakukan untuk menyandikan plaintext menjadi ciphertext dengan tujuan pesan tersebut tidak dapat dibaca oleh pihak yang tidak berwenang. Dekripsi merupakan proses yang dilakukan untuk memperoleh kembali plaintext dari ciphertext. Kunci yang dimaksud disini adalah kunci yang dipakai untuk melakukan dekripsi dan enkripsi. Kunci terbagi menjadi dua bagian, kunci pribadi (private key) dan kunci umum (public key). Perkembangan algoritma kriptografi modern berbasis bit didorong oleh penggunaan komputer digital yang merepresentasikan data dalam bentuk biner. Algoritma kriptografi yang beroperasi dalam mode bit dapat dikelompokkan menjadi dua kategori yaitu Cipher aliran (stream cipher), algoritma kriptografi beroperasi pada plaintext dan ciphertext dalam bentuk bit tunggal, yang dalam hal ini rangkaian bit dienkripsikan atau didekripsikan bit per bit [10]. Cipher blok (block cipher), algoritma kriptografi beroperasi pada plaintext dan ciphertext dalam bentuk blok bit, yang dalam hal ini rangkaian bit dibagi menjadi blok-blok bit yang panjangnya sudah ditentukan sebelumnya. Misalnya panjang blok adalah 64 bit, maka itu berarti algoritma enkripsi memperlakukan 8 karakter setiap kali penyandian $(1$ karakter $=8$ bit dalam pengkodean ASCII) [11].

\subsection{Algoritma RC4}

RC4 merupakan jenis aliran kode yang berarti operasi enkripsinya dilakukan per karakter 1 byte untuk sekali operasi. Algoritma kriptografi Rivest Code 4 (RC4) merupakan salah satu algoritma kunci simetris dibuat oleh RSA Data Security Inc (RSADSI) yang berbentuk stream cipher [12]. Algoritma ini ditemukan pada tahun 1987 oleh Ronald Rivest dan menjadi simbol keamanan RSA (merupakan singkatan dari tiga nama penemu yaitu Rivest, Shamir, dan Adleman) [13]. Secara garis besar algoritma dari metode RC4 Stream Cipher ini terbagi menjadi dua bagian, yaitu Key Setup atau Key Schedulling Algorithm (KSA) dan Stream Generation atau Pseudo Random Generation Algorithm (PRGA) dan proses XOR dengan stream data [13].

\section{Metode Penelitian}

Untuk membantu dalam penyusunan penelitian ini, maka perlu adanya susunan kerangka kerja (frame work) yang jelas tahapan-tahapannya. Kerangka kerja ini merupakan langkah-langkah yang akan dilakukan dalam penyelesaian masalah yang akan dibahas. Adapun kerangka kerja penelitian yang di gunakan seperti terlihat pada Gambar 1. 


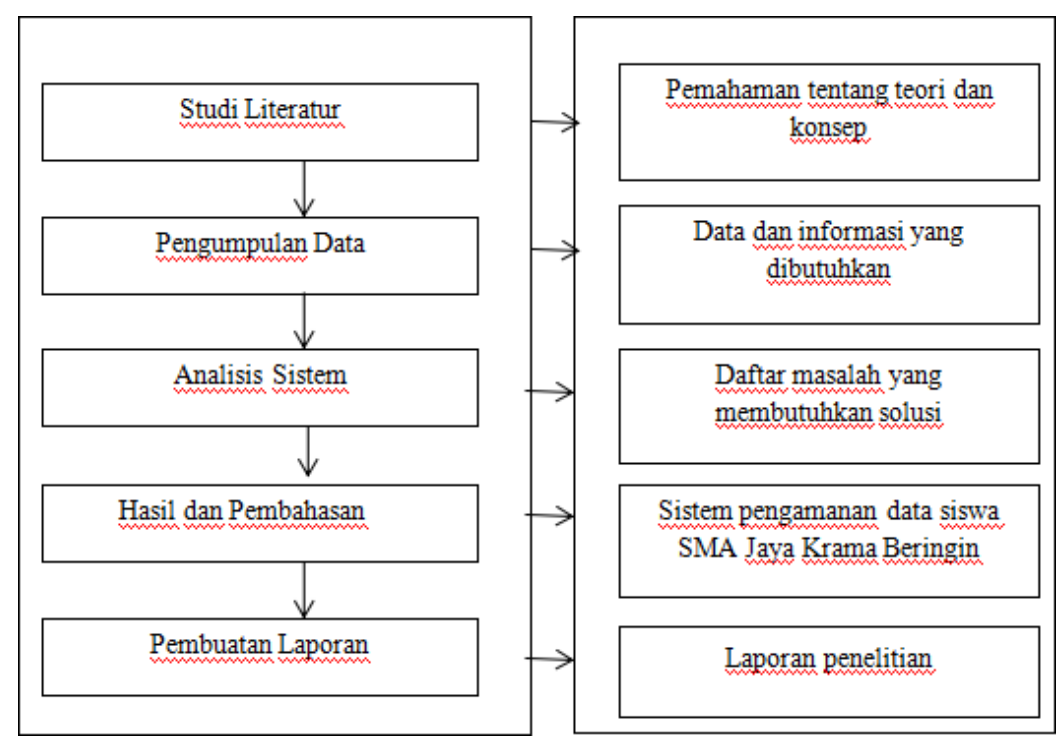

Gambar 1. Metode Penelitian

Tahapan metode penelitian :

1. Studi Literatur

Studi literatur yang dilakukan oleh dengan melakukan pencarian terhadap berbagai sumber tertulis, baik berupa buku-buku, arsip, majalah, artikel, dan jurnal, atau dokumen-dokumen yang relevan dengan permasalahan yang dikaji.

2. Pengumpulan data

Pengumpulan data dilakukan untuk memperoleh informasi yang dibutuhkan dalam rangka mencapai tujuan penelitian. Sebelum melakukan penelitian, seorang peneliti biasanya telah memiliki dugaan berdasarkan teori yang digunakan, dugaan tersebut disebut dengan hipotesis. Untuk membuktikan hipotesis secara empiris, seorang peneliti membutuhkan pengumpulan data untuk diteliti secara lebih mendalam.

3. Analisis Sistem

Analisis sistem adalah tahapan penelitian terhadap sistem berjalan dan bertujuan untuk mengetahui segala permasalahan yang terjadi serta memudahkan dalam menjalankan tahap selanjutnya yaitu tahap implementasi. 4. Hasil dan Pembahasan

Pada tahap ini, telah mendapatkan hasil dari kegiatan analisis yang dilakukan pada tahap sebelumnya. Hasil analisis akan dijabarkan secara mendetail melalui tabel-tabel dan hasil perhitungan rumus.

5. Pembuatan Laporan

Pada tahap ini, akan membuat laporan yang disusun berdasarkan hasil penelitan yang dilakukan. Laporan ini mencakup hasil analisis dari data-data yang telah dikumpulkan dangan menggunakan metode penelitian observasi.

\section{Hasil dan Pembahasan}

Analisis data adalah langkah pertama untuk melakukan penelitian membangun sebuah sistem. Data yang digunakan adalah data-data dari siswa SMA Swasta Jaya Krama beringin tahun ajaran 2020-2021. Data-data ini diperoleh hasil wawancara yang penulis lakukan kepada pihak sekolah staff administrasi SMA Swasta Jaya karma Beringin. Langkah pertama dalam tahapan Algoritma RC4 adalah melakukan proses KSA (Key Schedulling Algorithm) dimana pada tahap ini merupakan proses pembentukan S-Box (Array S) dengan panjang 256 byte (indeks 0 sampai 255) berdasarkan kunci enkripsi. Gambaran KSA dalam bentuk pseudocode :

For $\mathrm{i}=0$ to 255

$\mathrm{S}[\mathrm{i}]:=\mathrm{i}$

$\mathrm{J}:=0$

For $\mathrm{i}=0$ to 255

$\mathrm{j}:=(\mathrm{j}+\mathrm{S}[1]+\mathrm{key}[\bmod$ keylength] $) \bmod 256$

swap $(\mathrm{S}[\mathrm{i}], \mathrm{S}[\mathrm{j}])$ 
langkah kedua adalah PRGA (Pseudo-Random Generation algorithm) Tahap pseudo-random generation dimana state automaton beroperasi dan outputnya menghasilkan keystream. Setiap putaran, bagian keystream sebesar 1 byte (dengan nilai antara 0 sampai dengan 255) dioutput oleh PRGA berdasarkan state S. Berikut adalah algoritma PRGA dalam bentuk pseudo-code:

$\mathrm{i}=0 ; \mathrm{j}=\mathrm{i}$

for $\mathrm{i}=0<=$ jumlah_karakter_plaintext -1 do

$\mathrm{i}<=(\mathrm{i}+1) \bmod 25 \overline{6}$

$\mathrm{j}<=(\mathrm{j}+\mathrm{S}[\mathrm{i}]) \bmod 256$

swap (S[i], S[j] $\bmod 256$

$\mathrm{t}<=(\mathrm{S}[\mathrm{i}]+\mathrm{S}[\mathrm{j}] \bmod 256$

$\mathrm{K}<=\mathrm{S}[\mathrm{t}] \quad(*$ keystream*)

$\mathrm{c}<=\mathrm{K}+\mathrm{i}$

Sebagai contoh kasus mengenkripsi kata "rinaldimaulana" dengan kunci "negarakolombia", pertama inisialisasi S-Box dengan panjang 14 byte karena akan mengenkripsi plaintext dengan panjang 14 karakter, dengan $\mathrm{S}[0]=0, \mathrm{~S}[1]=1, \mathrm{~S}[2]=2, \mathrm{~S}[3]=3, \ldots \mathrm{S}[13]=13$ dan panjang kunci 14 byte juga sehingga terrbentuk array $\mathrm{S}$ dan array K. Selanjutnya mencampur operasi menggunakan variable i dan j menjadi indeks $\mathrm{S}[\mathrm{i}]$ dan $\mathrm{K}[\mathrm{j}]$, beri nilai awal untuk variable $\mathrm{i}$ dan $\mathrm{j}$ dengan 0.operasi campuran adalah pengulangan rumusan $(\mathrm{j}+\mathrm{S}[\mathrm{i}]$ $+\mathrm{K}[\mathrm{i}]$ mod 14 dan lakukan swap S[i] dan S[j],dengan menggunakan array dengan panjang 14 byte maka rumusnya :

For $\mathrm{i}=0$ to 14

$\mathrm{J}(\mathrm{j}+\mathrm{S}[\mathrm{i}]+\mathrm{K}[\mathrm{i}]) \bmod 14$

Swap $S[i]$ dan $S[j]$

maka nilai awal $\mathrm{i}=0$, sampai $\mathrm{i}=13$ akan menghasilkan array $\mathrm{S}$ :

Iterasi 1 :

$\mathrm{i}=0 \mathrm{~J}=(\mathrm{j}+\mathrm{S}[\mathrm{i}]+\mathrm{K}[\mathrm{i}]) \bmod 14=(0+0+110) \bmod 14=12$ swap $\mathrm{S}[0]$ dengan $\mathrm{S}[12]$

\begin{tabular}{|l|l|l|l|l|l|l|l|l|l|l|l|l|l|}
\hline 12 & 1 & 2 & 3 & 4 & 5 & 6 & 7 & 8 & 9 & 10 & 11 & 0 & 13 \\
\hline
\end{tabular}

iterasi 14 :

$\mathrm{i}=13 \mathrm{~J}=(\mathrm{j}+\mathrm{S}[\mathrm{i}]+\mathrm{K}[\mathrm{i}]) \bmod 14=(7+13+97) \bmod 14=5 \operatorname{swap} \mathrm{S}[13]$ dengan $\mathrm{S}[5]$

\begin{tabular}{|l|l|l|l|l|l|l|l|l|l|l|l|l|l|}
\hline 5 & 2 & 3 & 4 & 6 & 13 & 8 & 1 & 11 & 0 & 7 & 9 & 12 & 10 \\
\hline
\end{tabular}

Setelah mendapatkan nilai akhir untuk array S kemudian masuk ke fase PRGA dengan menggunakan operasi XOR untuk plaintext "rinadimaulana",karena plaintext yang akan dienkripsi panjang 14 karakter maka akan dilakukan 14 iterasi karena 1 kunci dan 1 kali pengoprasian XOR untuk tiap-tiap karakter pada plaintext. array yang digunakan untuk meng-XOR-kan adalah hasil akhir dari pencarian nilai array terakhir.

\begin{tabular}{|l|l|l|l|l|l|l|l|l|l|l|l|l|l|}
\hline \multicolumn{1}{|c|}{ Array S } \\
\hline 5 & 2 & 3 & 4 & 6 & 13 & 8 & 1 & 11 & 0 & 7 & 9 & 12 & 10 \\
\hline
\end{tabular}

Setelah mendapatkan kunci untuk setiap karakter kemudian dilakukan operasi XOR karakter pada plaintext dengan kunci yang didapat. berikut ini adalah tabel ASCII yang diubah ke biner pada plaintext yang digunakan. untuk mengembalikan chipertext menjadi plaintext kembali caranya dengan melakukan operasi XOR chipertext.

Table 1. Konversi Kode ASCII - Bilangan Biner

\begin{tabular}{|c|c|}
\hline PLAINTEXT & KODE ASCII TO BINER \\
\hline $\mathrm{r}$ & 01110010 \\
\hline $\mathrm{i}$ & 01101001 \\
\hline $\mathrm{n}$ & 01101110 \\
\hline $\mathrm{a}$ & 01100001 \\
\hline $\mathrm{l}$ & 01101100 \\
\hline $\mathrm{d}$ & 01100100 \\
\hline
\end{tabular}

Table 2. Proses Dekripsi

\begin{tabular}{|c|c|c|}
\hline Plaintext & Biner Key & Hasil XOR \\
\hline 01110010 & 000000101 & 01110111 \\
\hline 01101001 & 00001000 & 01100001 \\
\hline 01101110 & 00001000 & 01100110 \\
\hline 01100001 & 00001001 & 01101000 \\
\hline 01101100 & 00001101 & 01100001 \\
\hline 01100100 & 00001100 & 01101000 \\
\hline
\end{tabular}




\begin{tabular}{|c|l|}
\hline $\mathrm{i}$ & 01101001 \\
\hline $\mathrm{m}$ & 01101101 \\
\hline $\mathrm{a}$ & 01100001 \\
\hline $\mathrm{u}$ & 01110101 \\
\hline $\mathrm{l}$ & 01101100 \\
\hline $\mathrm{a}$ & 01100001 \\
\hline $\mathrm{a}$ & 01101110 \\
\hline
\end{tabular}

\begin{tabular}{|l|l|l|}
\hline 01101001 & 00001100 & 01100101 \\
\hline 01101101 & 00000000 & 01101101 \\
\hline 01100001 & 00000000 & 01100001 \\
\hline 01110101 & 00001010 & 01111111 \\
\hline 01101100 & 00000111 & 01101011 \\
\hline 01100001 & 00000111 & 01100110 \\
\hline 01101110 & 00001100 & 01100010 \\
\hline 01100001 & 00001000 & 01101001 \\
\hline
\end{tabular}

Setelah menggunakan operasi XOR pada chipertext dengan kunci,maka hasil XOR bilangan biner yang didapat diubah menjadi plaintext seperti yang terdapat di tabel 3. berikut ini adalah tabel perbandingan chipertext dan plaintext hasil dari dekripsi dengan kunci Algoritma RC4, Tabel 4.

Tabel 3. Plaintext dari hasil proses dekripsi

\begin{tabular}{|c|c|}
\hline Kode Biner Plaintext & Plaintext \\
\hline 01110010 & $\mathrm{r}$ \\
\hline 01101001 & $\mathrm{i}$ \\
\hline 01101110 & $\mathrm{n}$ \\
\hline 01100001 & $\mathrm{a}$ \\
\hline 01101100 & $\mathrm{l}$ \\
\hline 01100100 & $\mathrm{~d}$ \\
\hline 01101001 & $\mathrm{i}$ \\
\hline 01101101 & $\mathrm{~m}$ \\
\hline 01100001 & $\mathrm{a}$ \\
\hline 01110101 & $\mathrm{u}$ \\
\hline 01101100 & $\mathrm{l}$ \\
\hline 01100001 & $\mathrm{a}$ \\
\hline 01101110 & $\mathrm{n}$ \\
\hline 01100001 & $\mathrm{a}$ \\
\hline
\end{tabular}

Tabel 4. Hasil perbandingan chipertext menjadi

\begin{tabular}{|c|c|}
\hline \multicolumn{2}{l}{ plaintext } \\
\hline Chipertext & Plaintext \\
\hline w & r \\
\hline a & i \\
\hline f & n \\
\hline h & a \\
\hline a & l \\
\hline h & d \\
\hline e & i \\
\hline m & m \\
\hline a & a \\
\hline DEL & u \\
\hline k & l \\
\hline f & a \\
\hline b & n \\
\hline i & a \\
\hline
\end{tabular}

Implementasi adalah tahap penerapan dan sekaligus pengujian bagi sistem berdasarkan hasil analisa dan perancangan. Implementasi sistem kriptografi untuk pengamanan data siswa di SMA Swasta Jaya Krama Beringin dengan Algoritma RC4 yang dihasilkan :

a. Halaman menu utama. Pada Halaman Meu Utama, dilakukan penginputan data siswa, selanjutnya klik Tombol Enkripsi, Deskripsi.

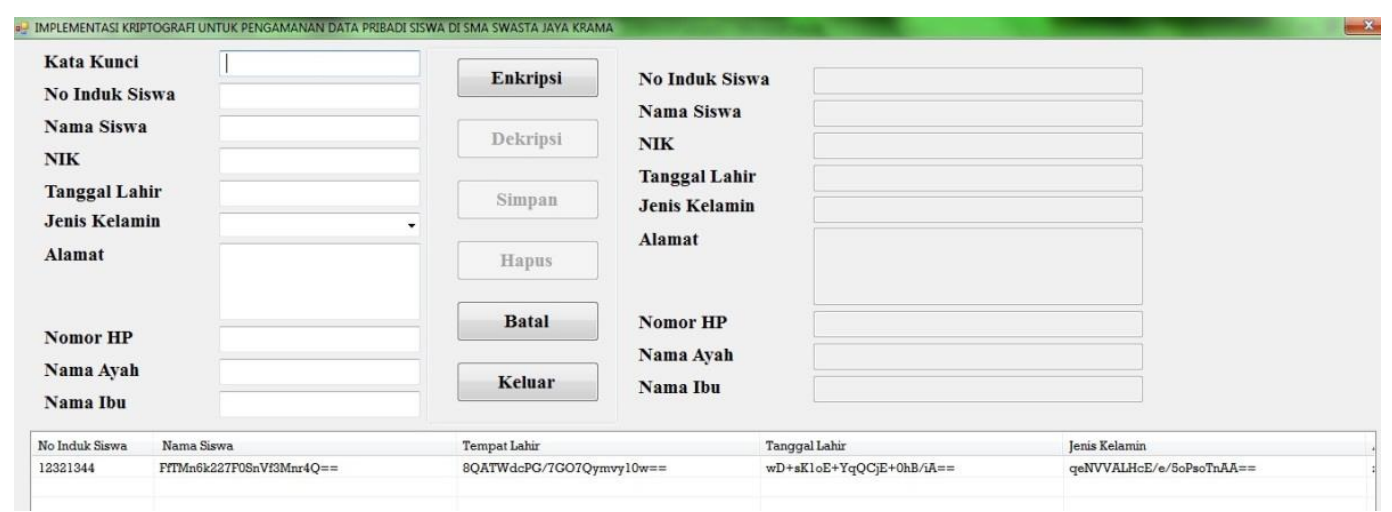

Gambar 2. Menu Utama 
b. Halaman Pengujian sistem input data sebelum di enkripsi, Gambar 3.

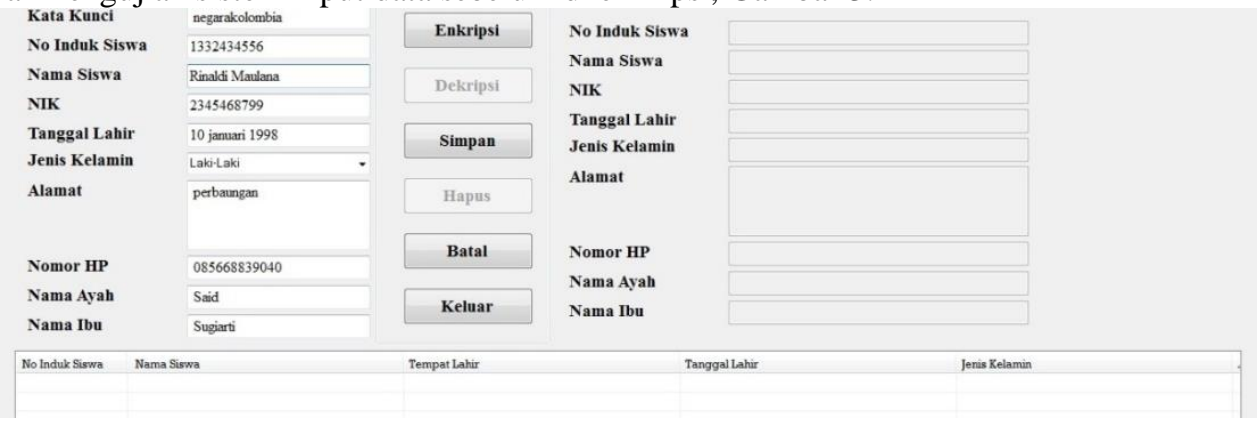

Gambar 3. Pengujian sistem input data sebelum di enkripsi

c. Data enkripsi yang berhasi disimpani, Gambar 4.

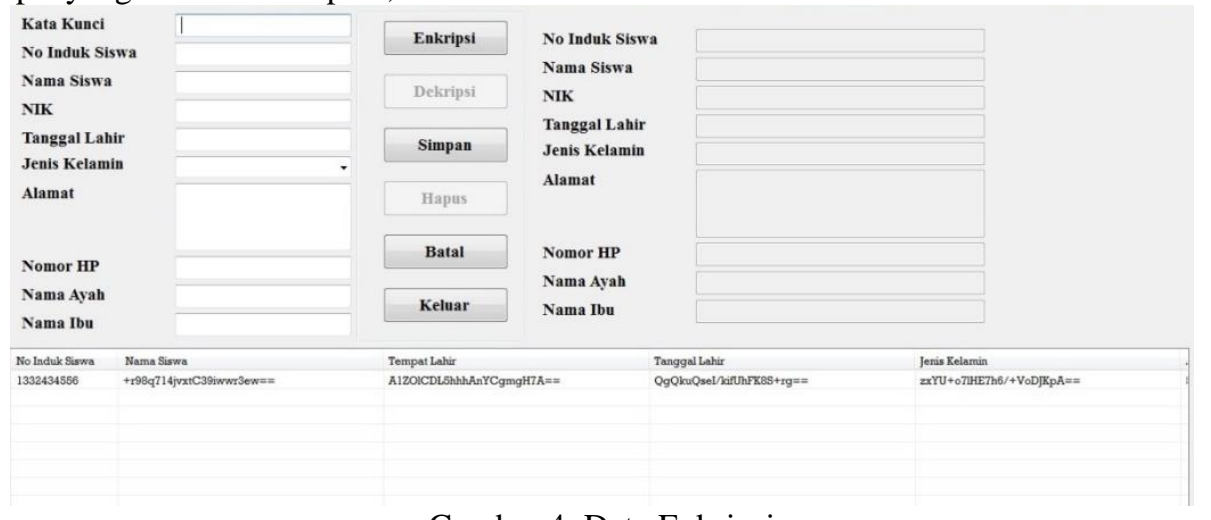

Gambar 4. Data Enkripsi

\section{Kesimpulan}

Kesimpulan penelitian :

1. Sistem mampu melakukan enkripsi pada data yang diinput sehingga dapat digunakan untuk meningkatkan keamanan data.

2. Algoritma RC4 dapat diimplementasikan untuk membuat sistem kriptografi keamanan data pribadi siswa SMA Swasta Jaya Krama Beringin.

3. Sistem yang dibuat dapat melakukan dekripsi pada teks enkripsi dengan kunci yang digunakan pada saat melakukan enkripsi.

\section{Daftar Pustaka}

[1] S. Nasional, T. Elektro, S. Informasi, and T. Informatika, "Seminar Nasional Teknik Elektro, Sistem Informasi, dan Teknik Informatika," vol. 4, pp. 121-128, 2021.

[2] M. Steganografi and A. Pada, "IMPLEMENTASI ALGORITMA KRIPTOGRAFI RC4 DAN," vol. 04, no. 02, pp. 81-88, 2017.

[3] N. Laila and A. S. R. Sinaga, "Implementasi Steganografi LSB Dengan Enkripsi Vigenere Cipher Pada Citra,”Sci. Comput. Sci. Informatics J., vol. 1, no. 2, p. 47, 2019.

[4] L. Silalahi and A. Sindar, "Penerapan Kriptografi Keamanan Data Administrasi Kependudukan Desa Pagar Jati Menggunakan SHA-1,” J. Nas. Komputasi dan Teknol. Inf., vol. 3, no. 2, 2020.

[5] K. A. Seputra, G. Arna, and J. Saskara, "KRIPTOGRAFI SIMETRIS RC4 PADA TRANSAKSI," vol. 17, no. 2, pp. 286-295, 2020.

[6] J. Pseudocode, S. Informasi, U. M. Bengkulu, and H. Cipta, "IMPLEMENTASI ALGORITMA RC4," vol. V, 2018.

[7] R. Y. Rifai, Y. Christyono, and I. Santoso, "SHAMIR ADLEMAN , DAN METODE STEGANOGRAFI UNTUK PENGAMANAN PESAN RAHASIA PADA BERKAS TEKS DIGITAL."

[8] F. S. Febriyani and A. Arfriandi, "Implementasi Algoritma RC4 pada Sistem Pengamanan Dokumen 
Digital Soal Ujian,” vol. 6, no. 3, pp. 171-177, 2021.

[9] T. Zebua and E. Ndruru, "PENGAMANAN CITRA DIGITAL BERDASARKAN MODIFIKASI ALGORITMA RC4,” vol. 4, no. 4, pp. 275-282, 2017.

[10] Novelius Buulolo and A. Sindar, "Analisis dan Perancangan Keamanan Data Teks Menggunakan Algoritma Kriptografi DES (Data Encryption Standard), J. Ilm. Teknol. Inf., vol. XV, no. November, pp. 61-65, 2020.

[11] C. V Synergy, "Pengamanan Dokumen Menggunakan Kriptografi RC4 dan Steganografi EOF dengan Media Video," vol. 8, no. 2, pp. 117-122, 2017.

[12] R. Sulaiman and B. Isnanto, "Peningkatan Keamanan Pesan Dengan Kriptografi RC4 dan Steganografi LSB Pada File JPEG,” pp. 8-9, 2018.

[13] A. R. Pambudi, "IMPLEMENTASI KRIPTOGRAFI PADA EMAIL MENGGUNAKAN ALGORITMA RIVEST CODE 4 ( RC4 ) DAN DATA ENCRYPTION STANDART ( DES ) BERBASIS JAVA DESKTOP PADA PT VEPRO,” vol. 1, no. 3, pp. 1267-1272, 2018. 